\title{
COMPARISON OF DENSITY MEASUREMENT METHODS FOR UNIDIRECTIONAL FLAX-EPOXY POLYMER COMPOSITES
}

\author{
YOUSEF SAADATI ${ }^{\dagger}$, JEAN-FRANÇOIS CHATELAIN $^{\dagger *}$, GILBERT LEBRUN $^{\dagger \dagger}$ \\ AND YVES BEAUCHAMP \\ $\dagger$ Mechanical Engineering Department \\ École de Technologie Supérieure (ÉTS) \\ 1100 Notre-Dame west, Montreal, Quebec, Canada \\ E-mail: yousef.saadati.1@ens.etsmtl.ca \\ *E-mail: jean-francois.chatelain@etsmtl.ca \\ ${ }^{\dagger \dagger}$ Mechanical Engineering Department \\ Université du Québec à Trois-Rivières (UQTR) \\ 3351, boul. des Forges, Trois-Rivières, Québec, Canada \\ E-mail: gilbert.lebrun@uqtr.ca, http://www.uqtr.ca/Gilbert.Lebrun \\ McGill University \\ 845 Sherbrooke Street West, Montreal, Québec, Canada \\ E-mail: yves.beauchamp@mcgill.ca
}

Key words: Natural Fibers, Flax Fiber, Epoxy Composites, Density Measurement, Fiberreinforced Composites, Physical Properties

Abstract. Density is a decisive factor in determining one of the most important advantages of flax fiber-reinforced polymer (FFRP) composites, i.e. their relatively low weight leading to high specific properties. As a fundamental physical property of composites, density enters in many engineering design and quality control calculations and its value is a determining factor for several applications. Especially, we need precise material properties including density so as to develop efficient numerical models to these materials. In this work, three density measurement methods were evaluated and compared: Helium-gas pycnometry and Archimedes with two different immersing liquids, water and ethanol. The results show that Helium-gas pycnometry and Archimedes with ethanol gave similar and repeatable results, whereas using water resulted in much lower values. The density values were all in the range of reported values. However, Helium-gas pycnometry or Archimedes using ethanol are recommended for more precision in measuring the density of FFRP composites.

\section{INTRODUCTION}

Towards increasing demand for replacing conventional synthetic fibers with natural fibers as reinforcement in fiber-reinforced polymer (FRP) composites, flax fibers have found their place in the industry to replace man-made glass fibers. Flax is one of the oldest plant-based fibers and together with hemp, jute, ramie and kenaf fibers are classified as bast fibers which are nowadays extensively used in the composite field [1,2]. Flax fibers are extracted from the stems of the flax plant and are composed of about $64 \%$ of cellulose. They normally come in 
bundles and at the mesoscopic level, a bundle contains 10 to 40 elementary fibers linked together by pectin. The elementary fibers, which have a 5-7-side polyhedron shape, have an extremely complex microstructure composed of concentric primary and secondary walls forming an open channel in the middle called lumen that contributes to water absorption [2,3].

Flax fibers are used in different forms as reinforcement in polymer composites, for instance, monofilament fibers, mats, rovings, yarns and fabrics. Nowadays, various fabrication technics are used to manufacture polymer composites, e.g. resin transfer molding (RTM), vacuum infusion, hand lay-up, film stacking, compression molding, injection molding and pultrusion $[2,3]$. In some studies, a variety of surface treatments have been applied to flax fibers to improve fiber-matrix adhesion, however, it is preferred to eliminate any extra procedure from the manufacturing process and use the fibers without any modifications [3-7]. J. Zhu [3] reported the resin transfer molding as a preferred processing method to produce high performance flax fiber-reinforced epoxy composites.

Flax has been used to reinforce many polymer matrices, including thermoplastics, thermosets and biopolymers, and each type has its advantages and disadvantages. Thermoset polymers are superior in terms of mechanical properties, chemical resistance, thermal stability and overall durability. As a thermoset polymer matrix, epoxy offers high mechanical performance and durability. It has attracted many researches and is the most commonly used matrix to produce flax fiber-reinforced polymer composites [2, 4, 8-10]. For that reason, epoxy has been chosen for matrix in the flax composite of this study.

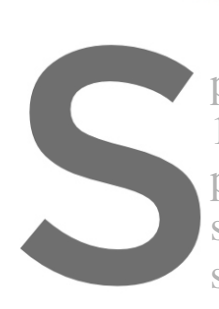

Flax/epoxy composit

performance and low density, factors of the hig
polymer (GFRP) composites, are potential alter
structural applications. They have found their
such as automotive, construction, packaging, spors
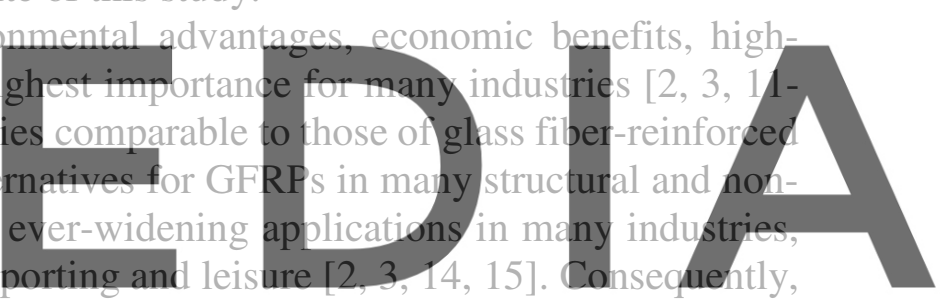

these composites need to be known very well in terms of physical and mechanical properties.

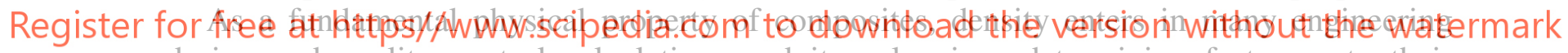

design and quality control calculations and its value is a determining factor as to their

application. Density determines one of the most important advantages of flax fiber-reinforced polymer (FFRP) composites, i.e. their relatively low weight leading to high specific properties. So we need precise material properties including density so as to develop efficient numerical models to these materials.

Although there are some works regarding the measurement of fiber density [16] and some others dedicated to the density measurement of flax fibers [17], the sensitivity of FFRP composites to different measurement methods has not been studied yet. The literature data are scattered, ranging from 1.117 to $1.32 \mathrm{~g} / \mathrm{cm}^{3}[2,18]$ and considering the fact that the density value depends on factors like the fiber volume fraction, fabrication process, measurement method and the condition of fibers used, it is often not possible to use values published in other studies. For the Finite Element Modeling (FEM) of the machining process of the FFRP composites used in this study, and in order to have a precise density value for them, this study has been conducted. Three methods to determine the density of unidirectional flax composites are evaluated and compared: Helium-gas pycnometry and Archimedes using two different immersing liquids, water and ethanol. The values will be compared and the possible sources of variations will be discussed. 


\section{MATERIALS AND TEST SPECIMENS}

Unidirectional flax fibers in the form of tapes with a surface density of $200 \mathrm{~g} / \mathrm{m}^{2}$, commercially named FlaxTape $^{\mathrm{TM}}$ (LINEO - France), were used as reinforcement and Marine 820 epoxy resin and Marine 824 hardener (ADTECH ${ }^{\circledR}$ Plastic Systems) as the polymer matrix to produce flax fiber-reinforced composite laminates. The flax/epoxy laminates were molded using the RTM process, as reported to be the preferred processing method to produce highperformance flax fiber-reinforced epoxy composites [3]. All laminates were molded in $300 \mathrm{~mm}$ $\times 300 \mathrm{~mm}$ dimensions, with $[0]_{\mathrm{n}}$ and $[0 / 90]_{\mathrm{n}}$ stacking sequences for the preparation of the test specimens. The thicknesses of the laminates were precisely calculated and controlled to result in a fiber volume fraction of $41 \%$ for all composites. The laminates were post-cured at $70^{\circ} \mathrm{C}$ and prepared for the cutting of specimens.

The test specimens were cut to fit in the considered location of test equipment and 5 specimens were prepared from identical laminates to check the repeatability of the tests. The samples were all stored in room conditions for 24 hours before testing to stabilize the temperature and humidity levels.

\section{EXPERIMENTAL PROCEDURES}

Three conventional methods, which are frequently used by researchers to determine the density of composites, were applied to measure the density of the FFRP composites: Heliumgas pycnometry, Archimedes (water used as immersing liquid) and Archimedes (ethanol used

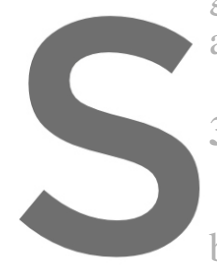
as immersing liquid).

\subsection{Helium-gas pycnometry}

Helium-gas pycnometry is a ved on which some commer
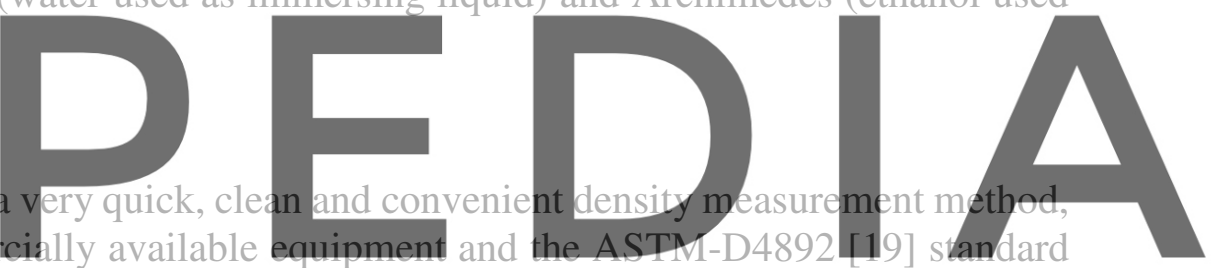

test method are developed. In this method, based on the volume of displaced gas and Boyle's

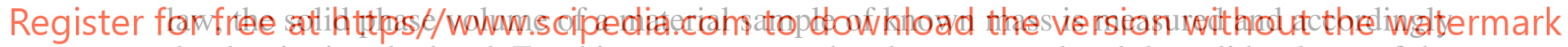
the density is calculated. For this purpose, two chambers are used and the solid volume of the specimen is calculated based on equation 1;

$$
V_{s}=V_{c}-\frac{V_{x}}{\frac{P_{1}}{P_{2}}-1}
$$

where the subscript $\mathrm{V}_{\mathrm{s}}$ refers to the sample volume, $\mathrm{V}_{\mathrm{c}}$ to the sample chamber volume, $\mathrm{V}_{\mathrm{x}}$ to the expansion chamber volume, $\mathrm{P}_{1}$ and $\mathrm{P}_{2}$ to the pressures after fill and after expansion respectively.

The disadvantage of this method is that from a certain level of pressure, Helium can enter into the open cavities so as to measure the density of the constituent materials of the composite rather than the composite density in its specific form and configuration. This issue will be evaluated by comparing the results with those of other methods.

An ACCUPYC ${ }^{\circledR}$ II gas displacement pycnometer device (a product of Micromeritics Instrument Corporation) was used in this work. The specimens and equipment are shown in figure 1 . The test was automatically repeated by the equipment 10 times for each sample, the average value was taken as the density of composite and the standard deviation was calculated. 


\subsection{Archimedes method}

This is a buoyancy method working based on the Archimedes' principle. It is simple to implement and has been traditionally used for measuring the density of materials. The ASTM D792 standard test method [20] has been developed based on this principle and is recommended for measuring the density of plastic materials. It has been used for measuring the density of composite in some works [21, 22]. A Sartorius YDK03 density measurement kit was used in this study, as shown in Figure 2. The density was calculated according to equation 2;

$$
\rho=\frac{W(a) \cdot[\rho(f l)-\rho(a)]}{W(a)-W(f l)}+\rho(\mathrm{a})
$$

where $\rho$ refers to the density, $\mathrm{W}$ refers to Weight, $(f l)$ refers to immersion fluid and $(a)$ to air. In order to monitor the absorption of liquid by the composite samples, the surface of the coupon was dried immediately after testing and the coupon reweighted.

\subsubsection{Water used as immersing liquid}

Water is the most commonly used liquid with this method. Due to the hydrophilic nature of natural fibers, immersing their composites in water may cause absorption of water by the fibers, thus affecting the value of measured density. In some studies water has been used to measure the density of natural fiber composites [21, 22]. In this method, the weight of the samples in the water started to increase without stabilizing. This is an evidence of absorbing water (rather than

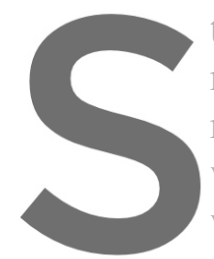
the removal of bubbles that stops in a short period of tim reweighting the samples. To avoid this rapidly wetted to remove the air bubbles suren water in a short time after immersion to avoid a water as immersing liqui the three measuring methods.
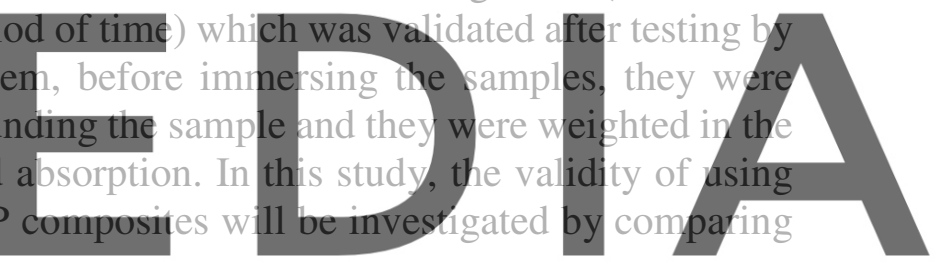

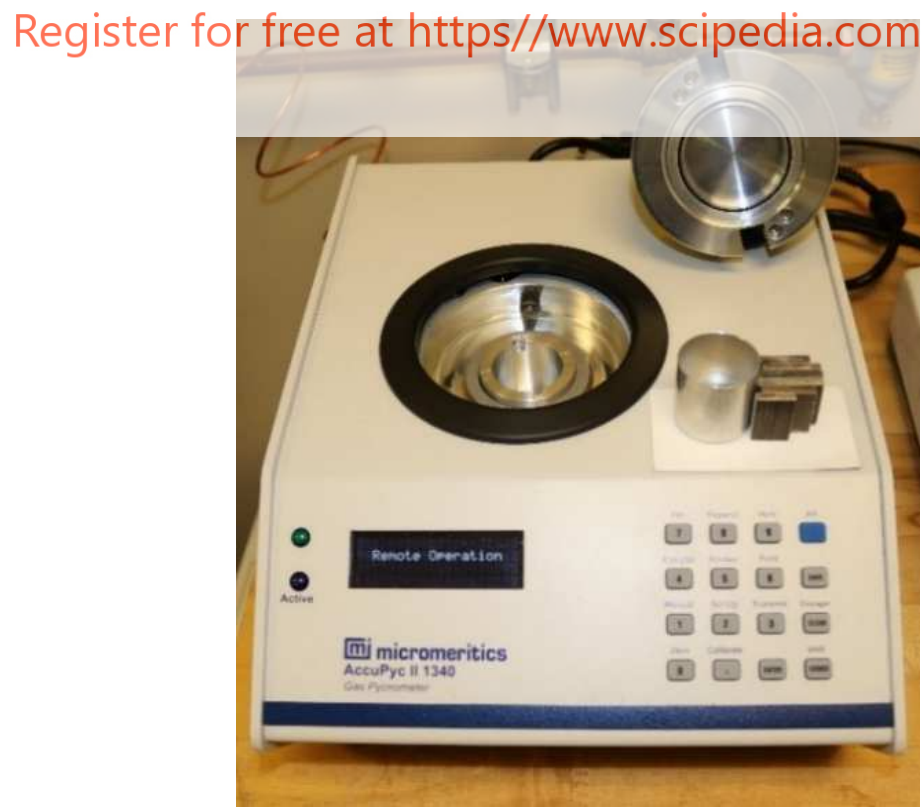

Figure 1: ACCUPYC ${ }^{\circledR}$ II Helium Gas Pycnometer

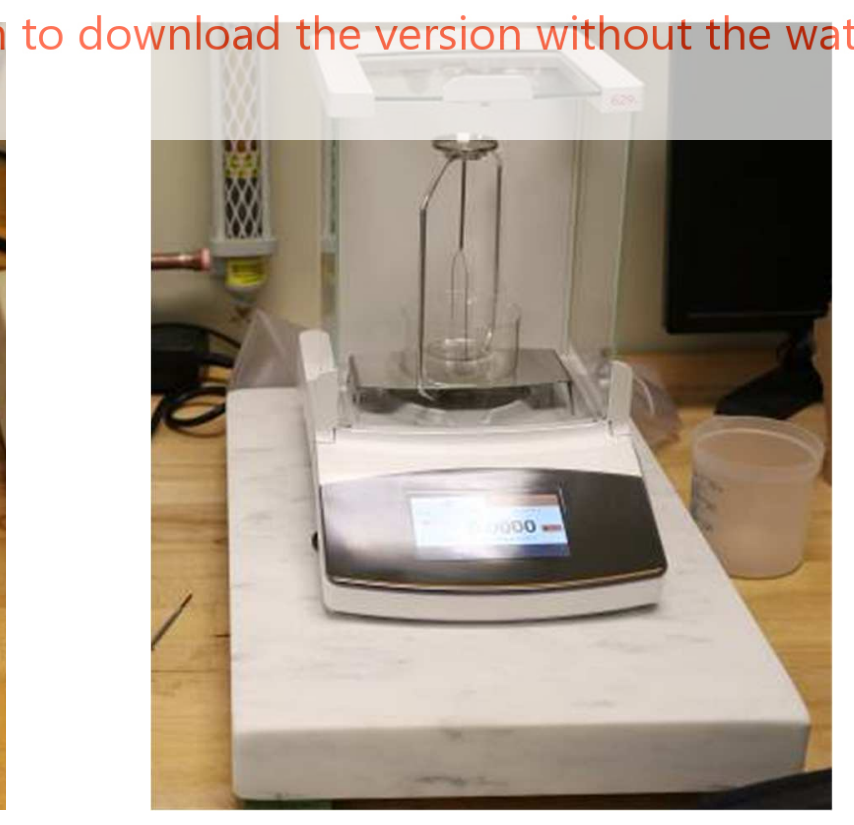

Figure 2: Sartorius YDK03 density measurement kit 


\subsubsection{Ethanol used as immersing liquid}

As an alternative to water, ethanol was used. It can be easily cleaned off, it doesn't affect the samples and it can be safely used in room conditions. It has been used by some researchers to measure the density of natural fibers $[23,24]$. The weight of samples in the ethanol was very well stabilized after a reasonable immersion time.

\section{RESULTS AND DISCUSSION}

For each method at least 5 tests were performed and the mean value of the measured densities are summarized and reported in table 1 . As can be seen, the gas pycnometry method resulted in nearly the same value for different samples.

Using Archimedes' method with water, in order to avoid the absorption of water by the samples, they were weighted in a short time after immersion. This resulted in lower specimen weight in the liquid (which may be due to remaining air bubbles) and consequently, in a lower density value (following Equation 2). Considering this issue and the fact that the samples need to be immersed in the fluid for a certain period of time to remove the air bubbles, it is concluded that measuring the density of FFRP composite by this method doesn't result in precise values.

Archimedes' method with ethanol allowed an immersion times long enough to remove the air bubbles and reach a stable weight. After testing, no weight change was observed, meaning that almost no ethanol was absorbed. Secondly, the very small coefficient of variation in Table 1 (for repeated samples) verify that a single physical property is measured. Finally, because the resulting value is very well correlated yith the result of gas pycnometry method, this mears
both methods can be recommended to gvaluate the density of natural fiber composites.
Talde 1: Meastred density values and its variations
$\begin{array}{cl}\text { Gas Pycnometry } & \text { Archimedes } \\ \text { (with Helium) } & \text { (with water) }\end{array}$

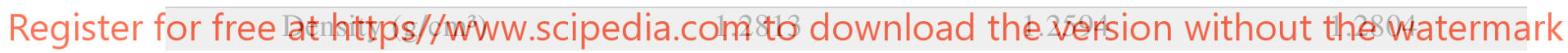 Standard deviation \\ 0.0005 \\ 0.0065 \\ 0.0009 \\ Coefficient of variation $(\%)$ \\ 0.04 \\ 0.52 \\ 0.07}

$\dagger$ Standard deviation/Mean value $* 100$

\section{CONCLUSION}

The density of FFRP composites was measured by three different methods, the results were compared to each other and discussed. According to the findings of this study, Archimedes' method using water as immersion fluid is not recommended for measuring the density of FFRP composites. Instead, Archimedes' using ethanol and the gas pycnometry methods are recommended as the results obtained from these methods were nearly the same.

\section{ACKNOWLEDGMENTS}

This research was supported by the National Research Council of Canada. We sincerely thank Mr. Daniel Poirier and his colleagues from CDCQ (Centre de développement des composites du Québec) for samples preparation as well as Radu Romanica, and Nabil Mazeghrane, who provided technical assistance that greatly assisted us in this research. 


\section{REFERENCES}

[1] Faruk, O., et al., Biocomposites reinforced with natural fibers: 2000-2010. Progress in Polymer Science (2012) 37(11): 1552-1596.

[2] Yan, L., N. Chouw, and K. Jayaraman, Flax fibre and its composites-A review. Composites Part B: Engineering (2014) 56: 296-317.

[3] Zhu, J., et al., Recent development of flax fibres and their reinforced composites based on different polymeric matrices. Materials (2013) 6(11): 5171-5198.

[4] Yan, L., N. Chouw, and X. Yuan, Improving the mechanical properties of natural fibre fabric reinforced epoxy composites by alkali treatment. Journal of Reinforced Plastics and Composites (2012) 31(6): 425-437.

[5] Van de Weyenberg, I., et al., Improving the properties of UD flax fibre reinforced composites by applying an alkaline fibre treatment. Composites Part A: Applied Science and Manufacturing (2006) 37(9): 1368-1376.

[6] Zhang, Y., et al., Tensile and interfacial properties of unidirectional flax/glass fiber reinforced hybrid composites. Composites Science and Technology (2013) 88: 172-177.

[7] Arbelaiz, A., et al., Flax fiber surface modifications: effects on fiber physico mechanical and flax/polypropylene interface properties. Polymer composites (2005) 26(3): 324-332.

[8] El Sawi, I., et al., Influence of the Manufacturing Process on the Mechanical Properties of Flax/Epoxy Composites. Journal of Biobased Materials and Bioenergy (2014) 8(1): 69-76.

[9] Charlet, K., et al., Mechanical properties of flax fibers and of the derived unidirectional composites. Journal of Composite Materials (2010) 44(24): 2887-2896.

[10] Lefeuvre, A., A. Bourmaud, and C. Baley, Optimization of the mechanical performance of UD flax/epoxy composites by selection of fibres along the stem. Composites Part A: Applied Science and Manufacturing (2015) 77: 204-208.

[11] Netravali, A.N. and S. Chabba, Composites get greener. Materials Today (2003) 6(4): 22-29.

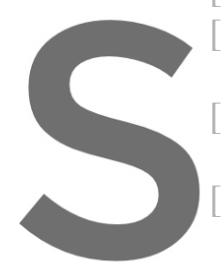

[12] Zini, E. and M

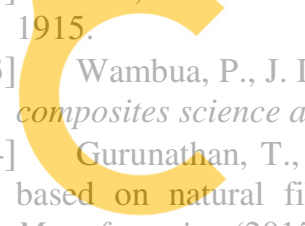

Manufacturing (2015) 77: 1-25.
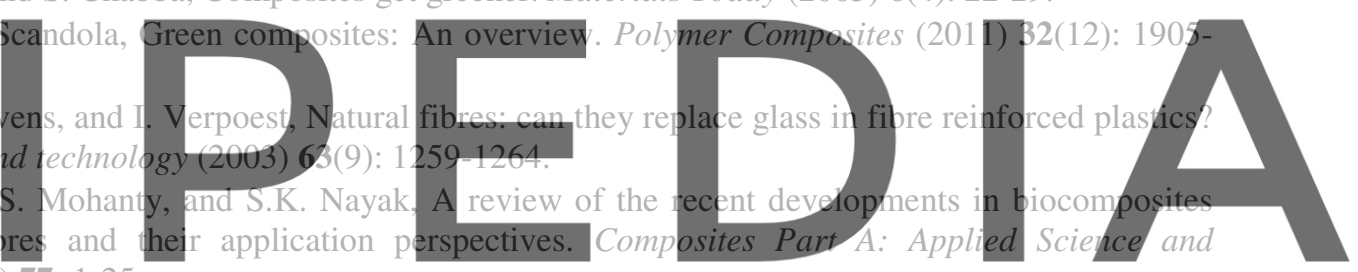

[15] Summerscales, J., et al., A. review of bast fibres and their composites. Part 1-Fibres as reinforcements.

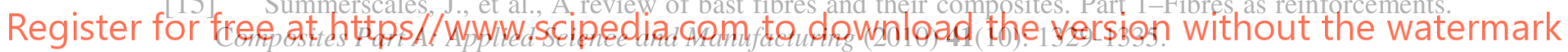

[16] Rude, T.J., L.H. Strait, and L.A. Ruhala, Measurement of Fiber Density by Helium Pycnometry. Journal of Composite Materials (2000) 34(22): 1948-1958.

[17] Amiri, A., et al., Standard density measurement method development for flax fiber. Industrial Crops and Products (2017) 96: 196-202.

[18] Mahmoudi, S., et al., Experimental and numerical investigation of the damping of flax-epoxy composite plates. Composite Structures (2018) 208: 426-433.

[19] ASTM, D4892-Standard Test Method for Density of Solid Pitch (Helium Pycnometer Method).

[20] ASTM, D792- Standard Test Methods for Density and Specific Gravity (Relative Density) of Plastics by Displacement.

[21] Madsen, B., Properties of plant fibre yarn polymer composites. Technical University of Denmark, (2004).

[22] Madsen, B. and H. Lilholt, Physical and mechanical properties of unidirectional plant fibre compositesan evaluation of the influence of porosity. Composites Science and Technology (2003) 63(9): 1265-1272.

[23] Truong, M., et al., A comparative study on natural fibre density measurement. The Journal of The Textile Institute (2009) 100(6): 525-529.

[24] Le Gall, M., et al., Recommended flax fibre density values for composite property predictions. Industrial Crops and Products (2018) 114: 52-58. 